\title{
Passive Open-Path FTIR Measurements and Spectral Interpretations for in situ Gas Monitoring and Process Diagnostics
}

\author{
S. CIECZCZYK* \\ Institute of Electronics and Information Technology, Lublin University of Technology, \\ Nadbystrzycka 38A, 20-618 Lublin, Poland \\ (Received May 7, 2014; in final form July 2, 2014)
}

\begin{abstract}
This article aims to present the possibilities for the passive spectral measurements and qualitative interpretations of inside-the-object gases. The basic features and applications of open-path Fourier transform infrared spectroscopy for measuring atmospheric and process exhaust gases are discussed. Methods for modelling and interpreting the spectra used for in situ measurements are presented. As an example, a spectrum simulation was investigated using $\mathrm{CO}_{2}$, a gas present in substantial quantities in various exhaust gases. The spectrum varied significantly with temperature allowing its use for diagnostics purposes. Thus, examples of measurements made using passive transmission with a heated object as a radiation source are presented. A baseline correction procedure was necessary to obtain a transmission (or absorbance) spectrum. The gas content and temperature were determined based on these measurements.
\end{abstract}

DOI: $10.12693 /$ APhysPolA.126.673

PACS: 07.07.Df, 07.57.Ty, 33.20.Ea, 07.05.Tp

\section{Introduction}

Optical methods are widely applied for gas measurements in various industrial fields and environmental monitoring [1]. With the aid of special equipment, one can process diagnostic information at a reaction site [2-4]. Under harsh industrial environments, spectral measurements can provide valuable information. However, despite their vast potential, in situ spectroscopic measurements are not commonly used largely due to the difficulties in obtaining information from the measured spectra. As with many indirect measurements a mathematical relationship between the desired process parameters and the directly measured values must be found $[5,6]$.

During pyrolysis and combustion, the gas content and temperature must be monitored. The predominant gases in these processes are carbon dioxide and water vapour. Gases such as $\mathrm{CO}, \mathrm{CH}_{4}, \mathrm{NO}_{x}$ and others may also be present in lower concentrations. Carbon dioxide is the main greenhouse gas that causes climate change. Carbon dioxide is often measured using a non-dispersive infrared (NDIR) technique, which can be applied to monitor stack emissions [7] or the air quality inside buildings. One problem with such measurements is the dependence of the sensor parameters on the temperature; however, attempts have been made to alleviate this issue [8]. New NDIR sensor systems can monitor $\mathrm{CO}_{2}$ content over a broad range from the ppm scale to 20 vol. $\%$ for a $32 \mathrm{~mm}$ optical path length [9]. Spectral measurements of carbon dioxide can also be used to characterise

*e-mail: s.cieszczyk@pollub.pl the flow. Changes in the rotational line intensity can mirror the state of flow [10]. Due to its high absorption, the $\mathrm{CO}_{2}$ spectral band between 2200 and $2400 \mathrm{~cm}^{-1}$ is used to estimate the temperature. The temperature profile of the spectrometer line of sight is measured using a spectral remote-sensing method [11, 12]. However, this method can introduce a strong absorption from atmospheric $\mathrm{CO}_{2}$ causing significant errors. Thus, the spectral band near $2270 \mathrm{~cm}^{-1}$, in which this effect is negligible, is applied [13]. The measurement of $\mathrm{CO}_{2}$ using a spectrally narrow quantum cascade detector with a Fourier transform spectrometer is also proposed [14].

Fourier transform infrared (FTIR) spectroscopy is widely used to measure various gases, often in the analysis of gases derived from the thermal degradation of biomass $[15,16]$. This technique is also used to measure the scattering by particles, such as water vapour [17]. Light extinction of particles can significantly impact the absorption measurements of the medium $[18,19]$. The primary advantage to this method is its ability for simultaneous qualitative and quantitative analyses of multiple components. Open-path FTIR (OP-FTIR) spectroscopy measures the transmission path in the atmosphere. The integrated concentration along the length of the measured path is then quantified. The spectrometer is characteristically independent from the radiation source. There is no sampling system separate from the test object and no need to store, dry or cool the samples. The active version utilises an additional radiation source.

In the passive version, the radiation derives from natural sources, such as the sun or hot gases. However, this case requires the use of an emission or absorption spectrum. If the studied gas layer is located between 
the layers or an element of higher temperature, then an absorption spectrum is obtained. If the measured layer has a temperature higher than the ambient temperature, then an emission spectrum will be observed. The passive method is less sensitive than the active method, particularly when the temperature in the gas layer of interest is near the ambient temperature. The advantage to these approaches, in comparison with active openpath absorption measurements, especially under industrial conditions, is that they do not require adjustments to the source or spectrometer. Exemplar measurements for assessing fire gases are obtained at $180^{\circ} \mathrm{C}[20]$. This method also works well for analysing the thermal decomposition of sewage sludge [21]. An interesting practical application of the passive technique is the quantification of exhaust gases from aircraft engines [22]. OP-FTIR is also frequently used to measure the gaseous emissions from the combustion of biomass [23].

In industry, emission spectroscopy is typically used to measure the radiation spectra of flames. This technique is clearly most commonly associated with temperature measurements. However, attempts have been made to determine the contents of both soot and a homogeneous layer containing water vapour and $\mathrm{CO}_{2}$ gases [24]. This method is attractive primarily because it is capable of remote sensing; for example, it can be used in environments such as volcanoes where other methods become difficult [25].

The semi-active method introduces a radiation source whose size corresponds to that of the spectrometer field of view [26]. This method does not require accurate alignment between the source and the spectrometer. The radiation source has a lower temperature than that in the classic active system; however, its temperature exceeds that of the passive system.

\section{Modelling of gas spectra}

Calibration involves building a model between the spectrum and the content of the specific components. Classical calibration requires the measurement of highquality calibration samples with an appropriate concentration range adapted to the specific application. Special equipment, such as a ventilation test chamber, may be used for this purpose [27]. During the calibration process one must maintain a constant temperature, pressure and pressure uniformity along the gas cell length.

The classical least-squares (CLS) technique can be used to precisely measure atmospheric gases. Spectral ranges are selected such that the absorbance does not exceed 0,4. For CO, this range is $2020-2200 \mathrm{~cm}^{-1}$; for ${ }^{12} \mathrm{CO}_{2}$, it is $2020-2306 \mathrm{~cm}^{-1}$; and for ${ }^{13} \mathrm{CO}_{2}$, it is $2020-2290 \mathrm{~cm}^{-1}$ [28]. To continuously monitor atmospheric gases the range of $2150-2320 \mathrm{~cm}^{-1}$ for $\mathrm{CO}_{2}, \mathrm{CO}$ and $\mathrm{N}_{2} \mathrm{O}$ retrieval is used [29]. The CLS method can be applied only over small ranges of the concentrationpath length product because the concentration can be underestimated at higher values [30]. Another popu- lar method for analysing open-path spectra is the partial least-squares (PLS) method [31]. Significant nonlinearity and thus Beer's law derogating can occur if the absorbance the spectral lines exceeds 0.5 [32]. This situation limits the possibility of using linear CLS and PLS methods or forces the use of weaker spectral lines. For quantitative analysis of the spectra, a neural network can be used as a non-linear method [33].

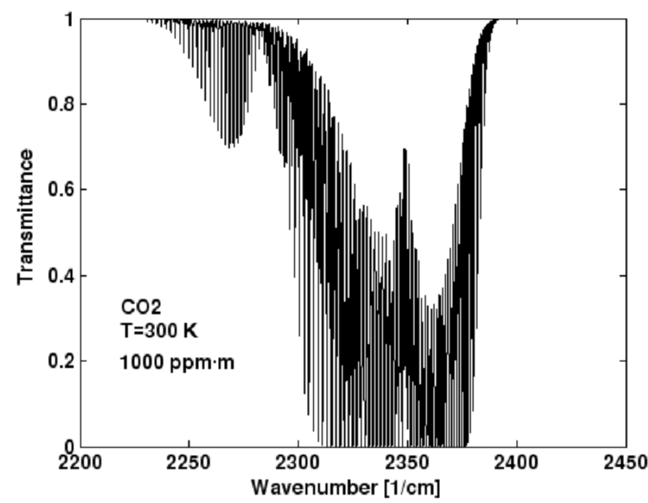

Fig. 1. $\mathrm{CO}_{2}$ transmittance at $300 \mathrm{~K}$ (infinite resolution).

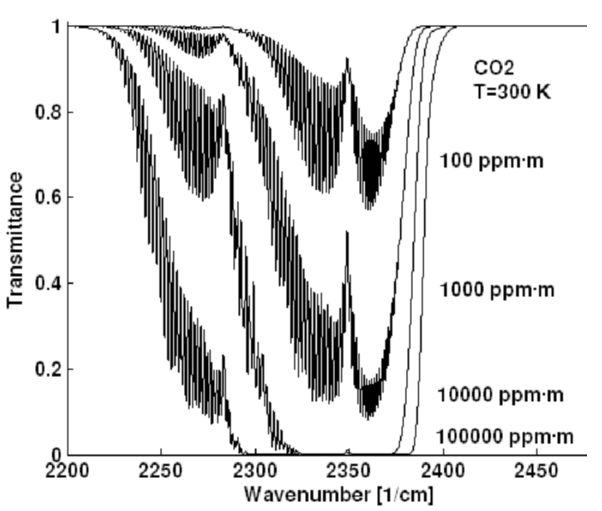

Fig. 2. $\mathrm{CO}_{2}$ transmittance changes due to the concentration path length at $300 \mathrm{~K}\left(1 \mathrm{~cm}^{-1}\right.$ resolution).

In the open-path measurements, however, the dominant approach uses a forward model, by which the spectrum can be determined based on the temperature, pressure, and gas content. To determine content, one must solve the inverse problem, which typically uses a nonlinear least-squares method. Because a mathematical solution to the inverse of the forward model is impossible, an iterative process is applied. The synthetic data from direct modelling are compared with the measured data (observations) until achieving an assumed fit. Similar mathematical approaches for inverse problems are used in various scientific fields. The solution method is often independent of the physical problem under consideration. Many inversion methods are available for which comparisons can be found in the literature [34-36]. A 


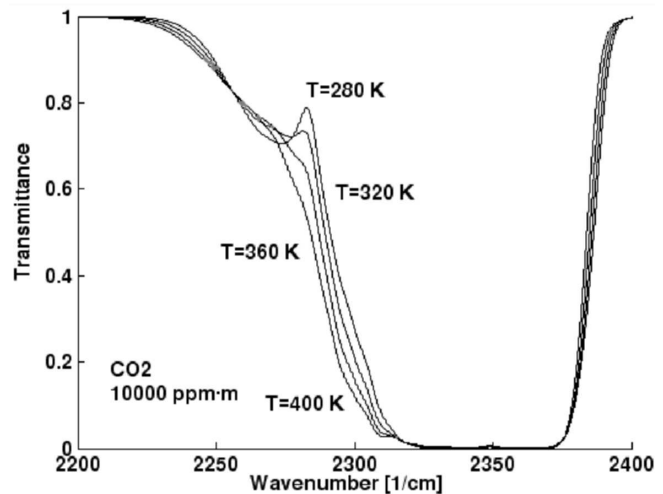

Fig. 3. Influence of temperature on transmittance for $10000 \mathrm{ppm} \mathrm{m} \mathrm{CO} 2\left(5 \mathrm{~cm}^{-1}\right.$ resolution $)$.

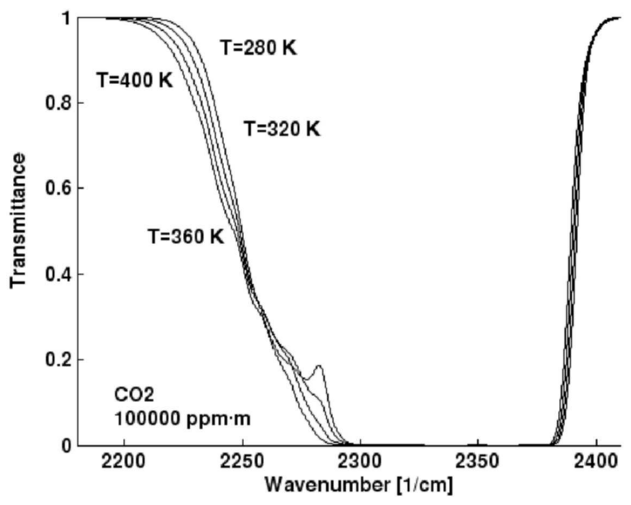

Fig. 4. Influence of temperature on transmittance of $100000 \mathrm{ppm} \mathrm{m} \mathrm{CO} 2\left(5 \mathrm{~cm}^{-1}\right.$ resolution).

direct model must take into account all gas and instrumental parameters because it can introduce errors, which can be significant if the instrument is misaligned [37]. Hence, the most important factor for interpreting the measurements is the creation of an appropriate direct model and an iterative procedure. The accuracy of the

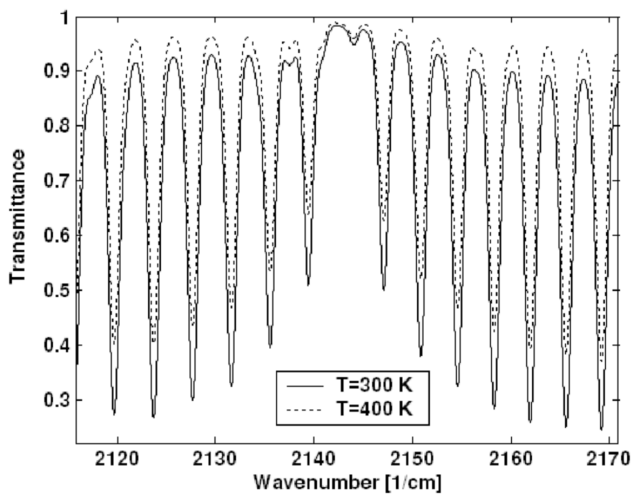

Fig. 5. Influence of temperature on transmittance of $7000 \mathrm{ppm} \mathrm{m} \mathrm{CO}\left(1 \mathrm{~cm}^{-1}\right.$ resolution). forward model should be verified for known measurement conditions. Open-path FTIR spectrometers are primarily used to measure atmospheric gases. Spectra obtained at temperatures that exceed those encountered under atmospheric conditions are used to verify the spectra calculated via simulation [38]. Experimental results are rarely presented in the literature. To determine the absorption coefficients of gases at high temperatures, a special cuvette is required. Accurate $\mathrm{CO}_{2}$ measurements at temperatures from 300 to $1550 \mathrm{~K}$ confirm the validity of the spectral model created using the line-by-line method and narrow-band databases, especially up to 600 K [39]. Similar high-resolution measurements have been made for industrial applications at temperatures up to $1773 \mathrm{~K}$ [40]. The spectral measurements at elevated temperatures also demonstrate good accuracy (up to $3 \%$ difference in the transmissivity) for different spectral models with $\mathrm{CO}_{2}$ and $\mathrm{H}_{2} \mathrm{O}$ used either in the spectroscopy or combustion processes for radiative transfer modelling [41-43]. The temperature can be determined from the absorption spectrum using the ratio of two absorption lines provided that optically thin conditions are utilised [44]. For example, the $2020-2100 \mathrm{~cm}^{-1}$ spectral range is used to determine of $\mathrm{CO}$ and $\mathrm{CO}_{2}$ [45]. Simulations of issues at hand can be performed to correctly analyse the measurement data [46] and the impact of various factors such as the temperature on the retrieval process [47]. For this purpose, the HITRAN database is utilised [48]. Figures 1-4 provide the $\mathrm{CO}_{2}$ transmissivity spectra for atmospheric concentrations and temperatures of exhaust gases created by different processes. The gas spectrum exhibits a strong characteristic absorption band at $2300-2400 \mathrm{~cm}^{-1}$. In this range, the transmittance is zero for concentrations above $1000 \mathrm{ppm} \mathrm{m}$. The $2200-2300 \mathrm{~cm}^{-1}$ range is sensitive to temperature changes depending on the concentration. As depicted in Fig. 5 temperature influence on the $\mathrm{CO}$ spectrum is also significant.

\section{Measurements and their analyses}

The main drawback to passive FTIR is the need for baseline correction. Algorithms can automatically perform this procedure; however, most require operator intervention. Manual correction to on-line measurements is difficult or even impossible. To perform an unattended operation, an automatic correction algorithm such as a wavelet transform is necessary [49]. The most common method utilises a polynomial held by the points of the spectrum without rotational line absorption [50], which implies the need for measurements with relatively high resolutions of at least $1 \mathrm{~cm}^{-1}$. At lower resolutions, the individual spectral lines may overlap making it difficult to find a point on the spectra with no absorption. Visibility of the individual rotational lines must be visible for compiling the background shape. Another method for determining the background involves the removal of all components from the spectra via iteration [51].

Measurements were made using a Bruker OPAG 33 spectrometer with a resolution of $1 \mathrm{~cm}^{-1}$. The measure- 
ment site was used to study the processes of biomass gasification and combustion. All measurements were obtained using the passive technique. The gas absorption features are shown in the spectrum because they were located between the hot regions of the structure and the spectrometer (Fig. 6). A typical spectrum is presented in Fig. 7. To retrieve the gas content using such measurements, the baseline spectra must first be estimated. A typical spectrum obtained after such an operation is presented in Fig. 8. A comparison between the atmospheric $\mathrm{CO}_{2}$ and the gases from biomass gasification in an $8 \mathrm{~m}$ path length is provided in Fig. 9. As indicated, the absorption of $\mathrm{CO}_{2}$ in the $2300-2400^{-1}$ spectral range is characteristically high. Significant CO absorption and several lines representing water vapour are also visible.

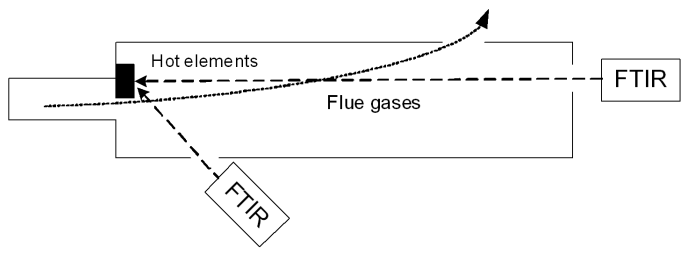

Fig. 6. Setup involving an FTIR spectrometer and biomass gasification of flue gases.

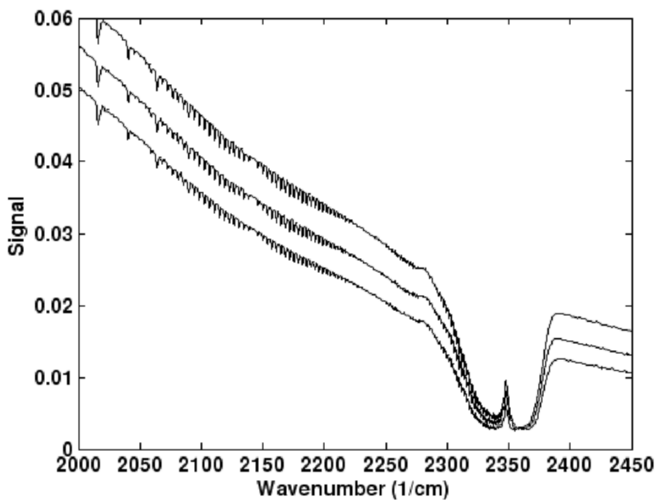

Fig. 7. Measured single-beam spectra for $\mathrm{CO}_{2}$ and $\mathrm{CO}$

Figure 10 provides the spectrum of $\mathrm{CO}_{2}$ measured at a $1 \mathrm{~cm}^{-1}$ resolution and smoothed by moving the average filter. Because the measured concentration and path length for atmospheric $\mathrm{CO}_{2}$ is low, absorption occurs in the range of $2320-2370 \mathrm{~cm}^{-1}$. Figure 10 clearly demonstrates the alignment between the measured spectrum and that derived from the direct model. This figure also indicates the correct baseline estimation obtained using a polynomial. The estimated value of the $\mathrm{CO}_{2}$ concentration is $950 \mathrm{ppm} \mathrm{m}$ (for $300 \mathrm{~K}$ ). After smoothing the rotational line is no longer visible, but filtering aids in increasing the quality of the match between the measured and calculated spectra for low signal-to-noise passive spectra. The large misfit between 2200 and $2250 \mathrm{~cm}^{-1}$ in Fig. 11 is

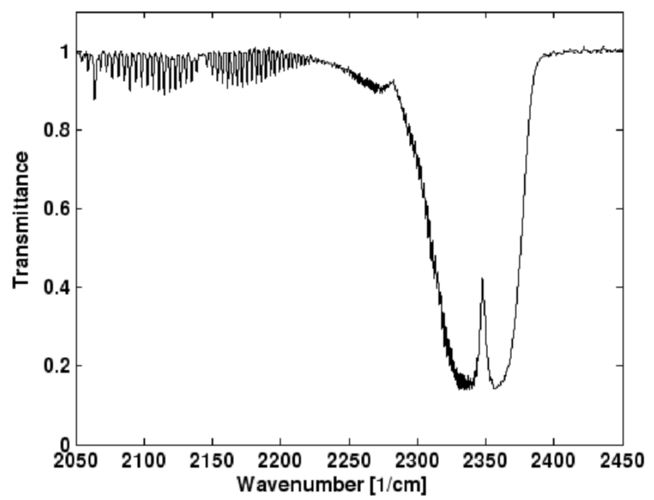

Fig. 8. Measured spectra after baseline correction.

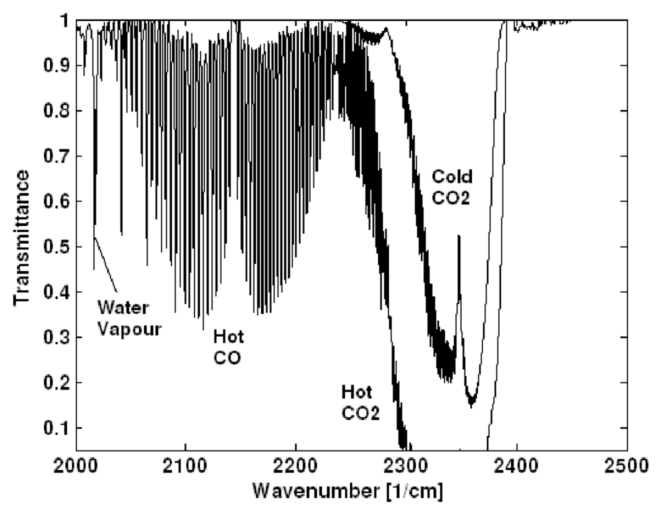

Fig. 9. Comparison of the measured spectra with cold atmospheric $\mathrm{CO}_{2}$ and warm, high-path length $\mathrm{CO}_{2}$ and $\mathrm{CO}$ concentrations.

due to interference from the $\mathrm{CO}$. The inversion procedure yielded a temperature of $360 \mathrm{~K}$ and a $\mathrm{CO}_{2}$ concentration of $21500 \mathrm{ppm} \mathrm{m}$.

Figure 12 provides a comparison of the measured and calculated spectra at $1 \mathrm{~cm}^{-1}$ resolution (without smoothing). The large values in the difference (residual) spec-

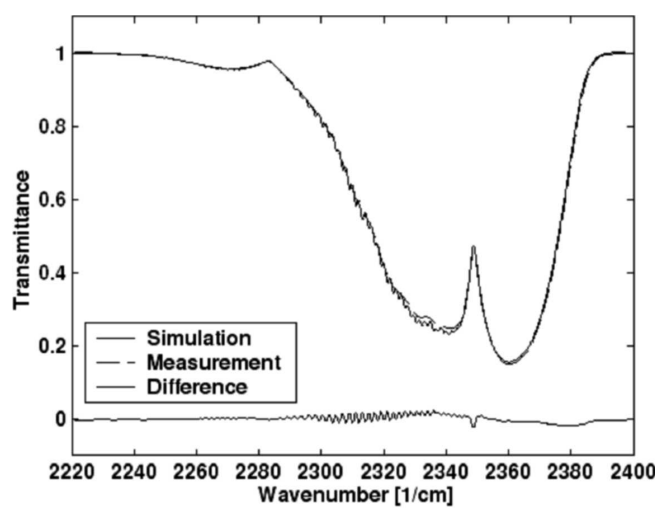

Fig. 10. Comparison between the measured and calculated spectra from the forward model after an iterative fitting for atmospheric $\mathrm{CO}_{2}$. 


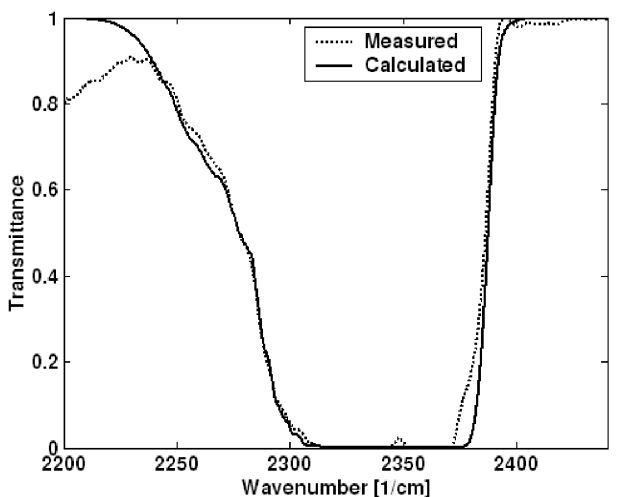

Fig. 11. Comparison between the measured and calculated spectra from the forward model after an iterative fitting for warm $\mathrm{CO}_{2}$ derived from biomass gasification.

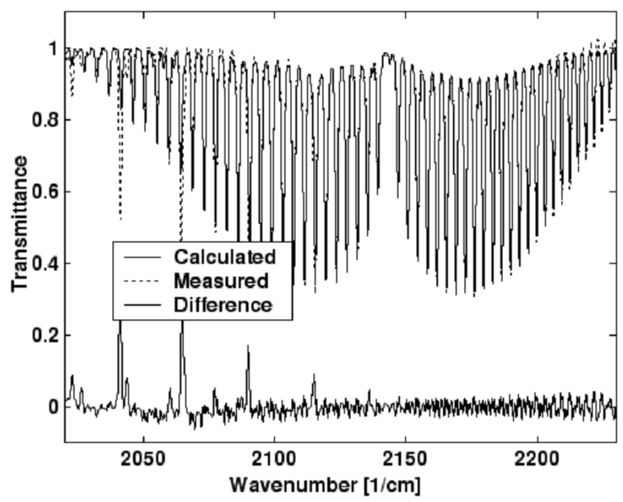

Fig. 12. Comparison of the measured and calculated spectra using the forward model after an iterative fitting for warm $\mathrm{CO}$ derived from biomass gasification.

trum are related to the water vapour absorption lines. Figure 12 clearly shows four such lines. Using detailed analysis for each CO rotational line (Fig. 13), a good fit can be obtained between the measurements and calculations, although the direct model only takes into account the shape of the ILS associated with the window applied to the interferogram. No ILS correction resulted from the field of view of the spectrometer. The example utilised an estimated path length of $7100 \mathrm{ppm} \mathrm{m}$ at $360 \mathrm{~K}$.

\section{Conclusions}

The temperature of gases measured in industrial processes using in situ methods can vary to a greater extent than those measured using conventional atmospheric OPFTIR. Therefore, three spectral windows wider than that found for atmospheric gas retrieval are needed. If, however, a wider spectral window is utilised to analyse passive gas absorption spectra, a proper background spectra must be selected. The use of conventional approximation via the polynomial method does not always produce the desired results. An iterative procedure that includes

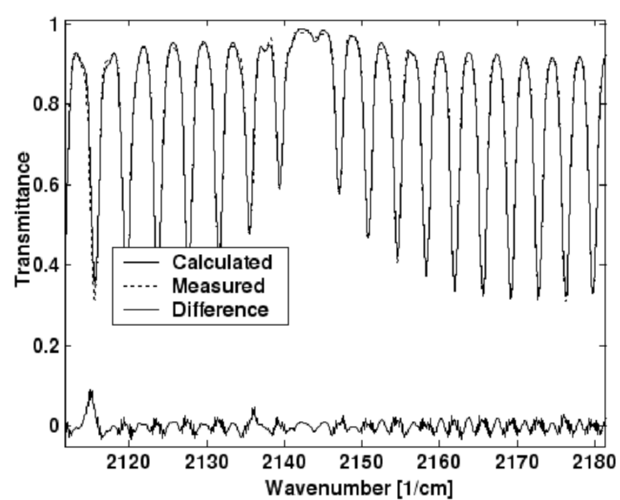

Fig. 13. Comparis on between the measured and calculated rotational lines spectra from the forward model after an iterative fitting for warm $\mathrm{CO}$ derived from biomass gasification.

correction for background spectra can improve the outcome of the algorithm for determining gas content. The correctness of the baseline may be evaluated using the difference between the measured and calculated spectra, which is particularly obvious in spectra containing evenly spaced rotational lines such as that of $\mathrm{CO}$. The residual spectrum has high-frequency components, which after integration within the bands approach or reach zero. These high-frequency components in the difference spectra can be interpreted as errors that arise from the simplicity of the ILS utilised. Therefore, a correct determination of the baseline requires low values of low-frequency components. The simulations, measurements and their comparison demonstrate the possibility of determining the content and temperature of gases via passive FTIR absorption with heated construction elements serving as a radiation source.

\section{References}

[1] J. Hodgkinson, R.P. Tatam, Meas. Sci. Technol. 24, 012004 (2013).

[2] J. Bak, S. Clausen, Meas. Sci. Technol. 13, 150 (2002).

[3] S. Rego-Barcena, R. Saari, R. Mani, S. El-Batroukh, M.J. Thomson, Meas. Sci. Technol. 18, 3479 (2007).

[4] S. Rego-Barcena, R. Mani, R. Saari, M. J. Thomson, Metall. Mater. Trans. B 40, 158 (2009).

[5] J. Mroczka, D. Szczuczyński, Metrol. Meas. Syst. 16, 333 (2009).

[6] D. Szczuczyński, J. Mroczka, Opt. Appl. 39, 521 (2009).

[7] Y.W.Sun, C. Liu, K.L.Chan, P.H. Xie, W.Q. Liu, Y. Zeng, S.M. Wang, S.H. Huang, J. Chen, Y.P. Wang, F.Q. Si, Atm. Measur. Techn. 6, 1993 (2013).

[8] J. Park, H. Cho, S. Yi, Procedia Eng. 5, 303 (2010).

[9] J. Hodgkinson, R. Smith, W.O. Ho, J.R. Saffel, R.P. Tatam, Sens. Act. B 186, 580 (2013). 
[10] W. Wong, Z. Yang, A. Muriel, ISRN Spectr. 2013, 681654 (2013).

[11] H. K. Kim, T. H. Song, J. Quant. Spectr. Radiat. Transf. 93, 369 (2005).

[12] T. Song, Heat Transf. Eng. 29, 417 (2008).

[13] H. Grosch, A. Fateev, K.L. Nielsen, S. Clausen, J. Quant. Spectr. Radiat. Transf. 130, 392 (2013).

[14] D. Hofstetter, J. Di Francesco, L. Hvozdara, H. P. Herzig, M. Beck, Appl. Phys. B 103, 967 (2011).

[15] A.J. de Castro, A.M. Lerma, F. Lopez, M. Guijarro, C. Diez, C. Hernando, J. Madrigal, Infrared Phys. Technol. 51, 21 (2007).

[16] A.V. Sepman, L.P.H. Goey, Biomass Bioen. 35, 2903 (2011).

[17] R.M. Hashmonay, M.G. Yost, Env. Sci. Techn. 33, 1141 (1999).

[18] M. Czerwiński, J. Mroczka, T. Girasole, G. Gouesbet, G. Grehan, Appl. Opt. 40, 1514 (2001).

[19] M. Czerwiński, J. Mroczka, T. Girasole, G. Gouesbet, G. Grehan,, Appl. Opt. 40, 1525 (2001).

[20] A. Stec, P. Fardell, P. Blomqvist, L. BustamanteValencia, L. Saragoza, E. Guillaume, Fire Safety J. 46, 225 (2011).

[21] J.H. Ferrase, S. Chavez, P. Arlabosse, N. Dupuy, Thermochim. Acta 404, 97 (2003).

[22] K. Schafer, C. Jahn, P. Sturm, B. Lechner, M. Bacher, Atm. Env. 37, 5261 (2003).

[23] I.R. Burling, R.J. Yokelson, D.W.T. Griffith, T.J. Johnson, P. Veres, J.M. Roberts, C. Warneke, S.P. Urbanski, J. Reardon, D.R. Weise, W.M. Hao, J. Gouw, Atm. Chem. Phys. 10, 11115 (2010).

[24] J. Lim, Y. Sivathanu, J. Ji, J. Gore, Combust. Flame 137, 222 (2004).

[25] C. Oppenheimer, P. Bani, J.A. Calkins, M. R. Burton, G. M. Sawyer, Appl. Phys. B 85, 453 (2006).

[26] T.J. Johnson, B.A. Roberts, J.F. Kelly, Appl. Opt. 43(3), 638 (2004)

[27] J. Raisanen, R. Niemela, Ann. Occup. Hyg. 46, 501 (2002).

[28] M.B. Esler, D.W.T. Griffith, S.R. Wilson, L.P. Steele, Analyt. Chem. 72, 206 (2000).

[29] S. Hammer, D.W.T. Griffith, G. Konrad, S. Vardag, C. Caldow, I. Levin, Atm. Measur. Techn. 6, 1153 (2013).

[30] T.E.L. Smith, M.J. Wooster, M. Tattaris, D.W.T. Griffith, Atm. Measur. Techn. 4, 97 (2011).

[31] D.L. Bjorneberg, A.B. Leytem, D.T. Westermann, P.R. Griffiths, L. Shao, M.J. Pollard, Trans. ASABE 52, 1749 (2009).
[32] L. Shao, P.R. Griffiths, P.M. Chu, T.W. Vetter, Appl. Spectrosc. 60, 254 (2006).

[33] S. Cięszczyk, Metrol. Meas. Syst. 2, 287 (2013).

[34] J. Mroczka, D. Szczuczyński, Appl. Opt. 49, 4591 (2010).

[35] J. Mroczka, D. Szczuczyński, Appl. Opt. 51, 1715 (2012).

[36] J. Mroczka, D. Szczuczyński, J. Quant. Spectr. Radiat. Transf. 129, 48 (2013).

[37] M.D. Coleman, T. Gardiner, Vibrat. Spectrosc. 51, 177 (2009).

[38] T. Fleckl, H. Jager, I. Obernberger, J. Phys. D: Appl. Phys. 35, 3138 (2002).

[39] M.F. Modest, S.P. Bharadwaj, J. Quant. Spectr Radiat. Transf. 73, 329 (2002).

[40] V. Evseev, A. Fateev, S. Clausen, J. Quant. Spectr. Radiat. Transf. 113, 222 (2012).

[41] V. Becher, S. Clausen, A. Fateev, H. Spliethoff, Int. J. Greenhouse Gas Contr. 5S, S76 (2011).

[42] V. Becher, S. Clausen, A. Fateev, H. Spliethoff, Int. J. Greenhouse Gas Contr. 5S, S66 (2011).

[43] V. Becher, A. Goanta, H. Spliethoff, Int. J. Greenhouse Gas Contr. 11, 34 (2012).

[44] G.P. Jellison, D.P. Miller, Opt. Eng. 45, 016201 (2006).

[45] M.J. Wooster, P.H. Freeborn, S. Archibald, C. Oppenheimer, G. J. Roberts, T.E.L. Smith, N. Govender, M. Burton, I. Palumbo, Atm. Chem. Phys. 11, 11591 (2011).

[46] J.Mroczka, Measurement 46, 2896 (2013).

[47] S. Cięszczyk, Metrol. Meas. Syst. 3, 513 (2013).

[48] L.S. Rothman, I.E. Gordon, Y. Babikov, A. Barbe, D. Chris Benner, P.F. Bernath, M. Birk, L. Bizzocchi, V. Boudon, L.R. Brown, A. Campargue, K. Chance, E.A. Cohen, L.H. Coudert, V.M. Devid, B.J. Drouin, A. Faytl, J.-M. Flaud, R.R. Gamachem, J.J. Harrison, J.-M. Hartmann, C. Hill, J.T. Hodges, D. Jacquemart, A. Jolly, J. Lamouroux, R.J. Le Roy, G. Li, D.A. Long, O.M. Lyulin, C.J. Mackie, S.T. Massies, S. Mikhailenko, H.S.P. Müllert, O.V. Naumenko, A.V. Nikitin, J. Orphal, V. Perevalov, A. Perrin, E.R. Polovtseva, C. Richard, J. Quant. Spectr. Radiat. Transf. 130, 4 (2013).

[49] L. Shao, P.R. Griffiths, Environm. Sci. Technol. 41, 7054 (2007).

[50] L. Zhi-Ming, L. Wen-Qing, G. Ming-Guang. T. JingJing, Z. Tian-Shu, X. Liang, W. Xiu-Li, Chin. Phys. $B$ 17, 4184 (2008).

[51] D. Hong, S. Cho, Appl. Spectrosc. 57, 299 (2003). 